\section{Tiger-bone trade could threaten lions}

The clampdown on the illegal trade in tiger parts for traditional Chinese medicines seems to be prompting their substitution with lion products (see our report Bones of Contention TRAFFIC/ WildCRU; in the press). Our investigations also reveal that measures to protect tigers in Asia may be driving a growing trade in other Asian felids.

Images of lions started to appear from about 1995 on the labels of Chinese medicines that traditionally would have contained tiger products. In December 2009, a CITES permit was issued in South Africa for lion skeletons to be exported to Asia - indicative of a developing market for the bones. Our report notes that more than 1,160 skeletons had been exported by the end of 2011, of which $85 \%$ were destined for the Lao People's Democratic Republic.

Controversially, the trade in lions from South Africa seems mostly to be a sustainable by-product of the trophyhunting industry (hunted lions are almost always bred in captivity). However, anecdotal accounts of wild lion poaching in other African countries for markets in Asia call for further investigation. And the trade in lion bones from South Africa may be linked with the sharp increase in rhino poaching in 2008, as discussed in our report. Vivienne L. Williams* University of the Witwatersrand, South Africa. vivwill@netdial.co.za

${ }^{*}$ On behalf of 4 correspondents (see go.nature.com/gvvklj for full list).

\section{Mind the gap in Hunt responses}

In my view, you use your publishing might irresponsibly in presenting Alessia Errico's article 'Judge by actions, not words' as the sole female riposte to Nobel laureate Tim Hunt's misogynistic remarks (Nature 522, 393; 2015).

Besides running contrary to

the groundswell of reaction from many scientists (see, for example, go.nature.com/gdvzvb), Errico's statement of support for Hunt's remarks was predictable. Hunt was her former supervisor: she depended on him for scholarship and career advancement.

Whether or not Hunt was joking and whether or not he apologized satisfactorily are beside the point. Neither is it likely that such outdated and seemingly entrenched attitudes can be dispelled by practical attempts to counter gender inequality in science (see Nature 522, 255; 2015 and D. Hilton Nature 523, 7; 2015).

Conspicuous by its absence in Nature so far is this: a woman commenting on the harm done by the flippant public denigration of women in science by a prominent scientist who is male. Rebecca Williams Jackson Big Rapids, Michigan, USA. rebecca.williams.jackson@post. harvard.edu

\section{Make pharma justify the price of drugs}

Some 500,000 people worldwide die from hepatitis $C$ virus every year because available remedies are unaffordable. So it is good to see expensive medicines against this virus, along with anticancer agents, included on the latest World Health Organization (WHO) Model Lists of Essential Medicines (see go.nature.com/wzah9w). However, simply listing these drugs is unlikely to make them more affordable, particularly in the developing world (see also www.msfaccess.org).

Health authorities must drive home the ethical obligation of pharmaceutical companies to cut the cost of life-saving medicines in accordance with the Doha Declaration of 2001, especially given that even some wealthy countries cannot afford them. To support this, governments and national health authorities should not grant patents on medicines that could be made more affordable.

Authorities should insist that drug firms make their costing information publicly available. This would include their investment in research and development compared with marketing expenditure, and details of differences between the actual cost and the retail price of medicines.

Such measures would enable the public to judge to what extent drug prices are the result of investment in innovation, rather than of satisfying shareholders and supporting marketing.

Vittorio Bertele', Silvio Garattini IRCCS - Mario Negri Institute for Pharmacological Research, Milan, Italy. vittorio.bertele@marionegri.it

\section{Focus on more specific fetal testing}

Most prenatal tests analyse a mix of maternal and placental DNA, and cannot distinguish the source of any abnormality (D. W. Bianchi Nature 522, 29-30; 2015). Our test, which was used to screen 185,000 women worldwide last year, reports specifically on fetal chromosomal status and so gets around the problem of validating incidental discoveries related to the mother's health.

The test detects single nucleotide polymorphisms (SNPs) in maternal and fetal DNA. The results are used to calculate a pregnancy-specific risk score; the maternal contribution is used only as input to the fetal-risk calculation (see B. Zimmermann et al. Prenat. Diagn. 32, 1233-1241; 2012). Therefore, incidental findings of maternal risk for cancer or abnormal numbers of sex chromosomes are not an issue. An exception is the partial deletion of chromosome 22 associated with DiGeorge syndrome. By providing the fetal-risk score, the test may identify the mother as a carrier of this deletion, as our consent form mentions.

Without knowing the sensitivities, specificities and positive or negative predictive values of incidental maternal findings, their clinical significance and utility are unknown. For example, there is currently no way to estimate residual risk when tests are negative for maternal cancer. Susan J. Gross, Stephanie Kareht, Allison Ryan Natera, San Carlos, California, USA. sgross@natera.com Competing financial interests declared: see go.nature.com/kgd6ik.

\section{Pollution hotspots tracked in real time}

As Beijing citizens, we are glad that China is prioritizing pollution monitoring as it starts to implement its new environmental protection law. Advances in environmental monitoring technology including wireless sensors, mobile apps and big-data processing - are raising public awareness and participation. These facilitate analysis by directly connecting researchers with government agencies and non-governmental organizations.

For example, wireless sensors installed on the chimney tops or drainage outlets of polluting factories monitor emissions such as sulfur dioxide and nitrogen oxides, or measure water contamination - all in real time. Big-data technology allows the rapid conversion of these massive data sets into regional and national insights that can be visualized online. For instance, real-time air-quality data from China's 367 major cities are mapped at www.cnemc.cn (in Chinese).

Xiaoyan Zheng, Yibing Lv China National Environmental Monitoring Center, Beijing, China. zhengxy@cnemc.cn 